\title{
Çocuklarda kardiyak cerrahi sonrası gelişen aritmi sıklığı ve risk faktörleri
}

\author{
Derya Karpuz ${ }^{1}$, Hasan Demetgül2, Dilek Giray¹, Olgu Hallığlu1 \\ ${ }^{1}$ Mersin Üniversitesi Tıp Fakültesi Pediatrik Kardiyoloji Ünitesi, Mersin, Türkiye \\ ${ }^{2}$ Hatay Devlet Hastanesi, Pediatrik Kardiyoloji Ünitesi, Mersin, Türkiye
}

Öz

Amaç: Kardiyak cerrahi sonrası gelişen aritmiler, sık görülen komplikasyon olmasına rağmen, genellikle önceden bir risk belirlemek olanaksızdır. Bu çalışmanın amacı pediatrik popülasyonda kardiyak operasyon sonrası gelişen ritim bozukluklarının tür ve sıklığını saptamaktır. Yöntem: Ocak 2008- Aralık 2015 tarihleri arasında çocuk kardiyoloji ünitesinde izlenen kardiyak operasyon geçirmiş, 2-17 yaş arası, 124 pediatrik hastanın (59'u kız, 65'i erkek) 24 saatlik holtermonitorizasyon kayıtları retrospektif olarak değerlendirildi. Hastaların demografik özellikleri, preoperatif tanıları ve geçirdikleri cerrahi girişim tipleri kaydedildi. Bulgular: Altmış sekiz hastada (\%54.8) aritmi olduğu saptandı. En sık görülen ritim bozuklukları supraventriküler ekstrasistol (SVE) ve ventriküler ekstrasistol (VES) olup her ikisinin de görülme sıklığı \%15.3 idi. Bu iki ritim bozukluğunun birlikte görülme oranı \% 12.9 bulundu. Kızlarda SVE ve VES görülme oranı biraz daha yüksekti. SVE ve VES riski sırasiyla atriyal septal defekt tamirinde \%26.3 ve \%7.9, ventriküler septal defekt tamirinde $\% 10.5$ ve \%15.8, tüm düzeltme yapılan Fallottetralojisinde ise $\% 4.5$ ve \%9.1 bulundu. Atriyal septal defekt tamiri yapılan bir hastada supraventriküler taşikardi, ventriküler septal defekt tamiri ve tüm düzeltme yapılan Fallottetralojisi olan iki hastada ise sürekli olmayan ventriküler taşikardi izlendi. Sonuç: Kardiyak operasyon geçiren hastaların izleminde aritmi gelişebileceği bilinmeli ve hastalara düzenli holter EKG izlemleri yapılmalıdır. Bu çalışmada en sık görülen postoperatif aritmi tiplerinin SVE ve VES olduğu ve atriyal septal defekt, ventriküler septal defekt ve Fallottetralojisi operasyonlarının aritmiler için risk faktörü olduğu gösterilmiştir.

Anahtar kelimeler: Aritmi, holter elektrokardiyografi, supraventriküler ekstrasistol, ventriküler ekstrasistol

Yazının geliş tarihi: 17.11.2017

Yazının kabul tarihi: 04.01.2018

Sorumlu yazar: DeryaKarpuz, Mersin Üniversitesi Tıp Fakültesi Çocuk Kardiyolojisi Bölümü, Çiftlikköy Kampüsü, 33343 Mersin / Türkiye.

Tel: 032424100 00, E-posta: drderyakarpuz@gmail.com

Not: Çalışma 15. Pediatrik Kardiyoloji ve Kalp Damar Cerrahisi Kongresinde (13-16

Nisan 2016/ Antalya) poster bildiri olarak sunulmuştur. 


\title{
Frequency and risk factors of arrhythmia developing after cardiac surgery in children
}

\begin{abstract}
Aim: Although arrhythmia is a common complication after cardiac surgery, it is usually impossible to identify a risk in advance. The aim of this study is to determine the type and frequency of arrhythmias developing after cardiac surgery in the pediatric population. Method: 24 hour holter monitorization records of 124 pediatric patients (n:59 girl, n:65 boy) aged 2-17 who undergo cardiac surgery were retrospectively evaluated between January 2008 and December 2015. Patients' demographic characteristics, preoperative diagnosis and types of cardiac surgery were recorded. Results: 68 (\%54.8) patients had arrhythmia. The most common arrhythmias were supraventricular extrasystole (SVE) and ventricular extrasystole (VES), and the frequencies of both were $15.3 \%$. The rate of both rhythm disorders being at the same time was $12.9 \%$.The rate of SVE and VES were slightly higher in girls. Respectively, the risk of SVE and VES were found as \%26.3 and \%7.9 in atrial septal defect repair surgery, $10.5 \%$ and $15.8 \%$ in ventricular septal defect repair surgery, 4.5 and $9.1 \%$ in total corrected fallot tetralogy. Supraventricular tachycardia in a patient with atrial septal defect repair surgery, non-sustained ventricular tachycardia in two patients with all corrected Fallot tetralogy and ventricular septal defect repair surgery were observed. Conclusion: It is known that patients undergo cardiac surgery may develop arrhythmian and regular holter ECG follow-ups should be performed. In this study The most common postoperative arrhythmia types are SVE and VES and atrial septal defect, ventricular septal defect, and tetralogy of Fallot have been shown to be risk factors for arrhythmias.
\end{abstract}

Keywords: Arrhythmia, holter electrocardiography, supraventricular extrasystole, ventricular extrasystole

\section{Giriş}

Kardiyak cerrahi sonrası gelişen aritmiler hem erken hem de geç dönemde sık görülen komplikasyon olmasına rağmen, genellikle önceden bir risk belirlemek olanaksızdır. Ritim bozuklukları normal bir kalpte iyi tolere edilebilirken, erken postoperatif dönemde oluştuğunda hemodinamik sorunlara yol açabilmektedir. Preoperatif dönemde basınç ve hacim yükü nedeniyle gelişen miyokardiyal disfonksiyon sonucu konjenital kalp hastaları postoperatif ritim sorunlarına karşı eğilimli olmaktadır. Kardiyopulmoner bypass, intraoperatif süreçte miyokardiyal ve iletim sisteminde oluşan hasar, postoperatif metabolik anormallikler, elektrolit bozuklukları, cerrahi strese karşı artmış adrenerjik yanıt ve inotropik ajanların kullanımının erken postoperatif dönemde aritmi riskini artırdığ bilinmektedir $^{1-4}$. Kalp cerrahisi sonrası gelişen aritmilerin sıklığı ve tipi yaşa, altta yatan lezyona, cerrahi tipine ve yerel uygulama şekillerine göre değişmektedir. Postoperatif aritmi sıklığ farklı yayınlarda \%8.0'dan \%79.1'e kadar değișen oranlarda bildirilmiştir5. Çoğu ritim sorunu geçici olmasına rağmen bir kısmı tedaviye dirençli, hatta hayatı tehdit edici olabilmektedir.

$\mathrm{Bu}$ çalışmanın amacı pediatrik popülasyonda kardiyak operasyon sonrası gelișen ritim bozukluklarının tür ve sıklı̆̆ını saptamaktır.

\section{Gereç ve Yöntemler}

Çalışmada Ocak 2008 - Aralık 2015 tarihleri arasında Mersin Üniversitesi Tıp Fakültesi Çocuk Kardiyoloji Ünitesinde izlenen kardiyak operasyon geçirmiş hastaların 24 saatlik holter monitorizasyon kayıtları retrospektif olarak incelendi. Standart ambulatuvar üç kanallı (V1, V5 ve aVF) 24 saat ritim holter kaylt cihazı kullanılarak monitorizasyonları yapılmış olan 2-17 yaş arası, 125 pediatrik hastanın holter 
elektrokardiyografi (EKG) kayıtlarına ulaşıldı. Hastaların demografik özellikleri, preoperatif tanıları ve geçirdikleri cerrahi girişim tipleri hasta bilgi sisteminden kaydedildi. Bu çalışma için hastane yerel klinik araştırmalar etik kurlundan onay alındı ( 2016/88).

Elde edilen verilerin dağılımına bakıldıktan sonra ortalama veya ortanca, standart sapma, en küçük en yüksek değer ve yüzde olarak sonuçlar özetlendi. Niteliksel verilerin analizinde "ki-kare testi" kullanıldı. $\mathrm{p}<0.05$ değeri istatistiksel olarak anlamlı kabul edildi.

\section{Bulgular}

Çalışmaya alınan 124 pediatrik hastanın 59'u (\% 47.2) klz, 65’i (\% 52.8) erkekti. Hastaların yaşları 2-17 yaş arasında (ortalama=9.1 \pm 3.6 yıl) değişmekteydi. Hastaların ritim holter EKG'leri değerlendirildiğinde 68 hastada (\%54.8) aritmi olduğu saptandı. En sık görülen ritim bozuklukları supraventriküler ekstrasistol (SVE) ve ventriküler ekstrasistol (VES) olup her ikisinin de görülme sıklığı \%15.3 idi. Bu iki ritim bozukluğunun birlikte görülme oranı ise \%12.9 bulundu. Cinsiyet yönünden anlamlı fark olmasa da kızlarda SVE ve VES görülme oranı erkeklere göre biraz daha yüksekti.

Supraventriküler ekstrasistol ve VES riski sirasiyla atriyal septal defekt (ASD) tamirinde $\% 26.3$ ve $\% 7.9$, ventriküler septal defekt (VSD) tamirinde \%10.5 ve \%15.8, tüm düzeltme yapılan Fallottetralojisinde ise $\% 4.5$ ve \%9.1 bulundu. Atriyal septal defekt tamiri yapılan bir hastada supraventriküler tașikardi, ventriküler septaldefekt tamiri ve tüm düzeltme yapılan Fallottetralojisi olan iki hastada ise non-sustained ventriküler taşikardi izlendi. Ventriküler septaldefekt tamiri yapilan bir hastada 2. derece blok saptandı. Kardiyak cerrahi tipleri ve izlemde gelişen ilişkili aritmi tipleri Tablo 1 de özetlenmiştir.

\section{Tartışma}

Bu çalışmada konjenital kalp hastalığı nedeniyle ameliyat olan çocuk hastalarda majör kardiyak cerrahi sonrası aritmi görülme sıklığı değerlendirildi. Kardiyak cerrahi sonrası postoperatif erken ve geç dönemde aritmilerin tipi ve sıklığı hakkında özellikle erişkinlerde çeşitli çalışmalar olsa da çocukluk yaş grubunda postoperatif aritmilerin insidans, tedavi ve risk faktörleri hakkında çok az şey bilinmektedir ${ }^{5-7}$.

Verilerimize göre kardiyak cerrahi sonrası geç dönem aritmi sıklığı \%54.8 olarak saptandı. Konjenital kalp hastalığı nedeniyle ameliyat olan çocuk hastalarda postoperatif dönemde yapılan çalışmalarda aritmi sıklığı farklı yayınlarda \%8.0'dan \%79.1'e kadar değișen oranlarda rapor edilmiștir. Pfammatter ve $\operatorname{ark}^{4}, 310$ hastada aritmi prevelansını \%27, Valsangiacomo ve ark. ${ }^{3}$ kalp cerrahisinden sonra ilk gün içerisinde \%48 oranında saptamışlardır. Başka bir kohort çalışmasında müdahale gerektiren aritmi oranının \%15 olduğu rapor edilmiștir. ${ }^{6}$ Alp ve $\operatorname{ark}^{7} 12$ lead EKG kullanılarak posoperatif erken dönemde aritmi pik prevelansını \% 43.5 bulmuşlardır. Kardiyak cerrahi geçiren 494 çocuk hastada ise holterEKG kullanıldığında aritmi prevelansı \%73.4 olarak gösterilmiştir. ${ }^{5}$ Çalışmamızda aritmi sıklığ literatür ile uyumludur. Sonuçlarımızın daha önce yapılan çalışmalardan bazılarına göre yüksek olmasının sebebi yatak başı monitör yerine 24 saat holter EKG kaydı kullanmamı ve dolayısıyla holter EKG'nin özellikle ekstrasistollere daha duyarlı olmasıyla açıklanabilir. 
Tablo 1: Kardiyak cerrahi tipleri ve cerrahi ile ilişkili aritmiler

\begin{tabular}{|c|c|c|c|c|c|c|c|c|c|c|c|}
\hline $\begin{array}{l}\text { Operasyon } \\
\text { tamlarn }\end{array}$ & SVE & VES & SVT & VT & $\begin{array}{l}\text { SVE+ } \\
\text { VES }\end{array}$ & $\begin{array}{l}1 . \\
\text { derece } \\
\text { blok }\end{array}$ & $\begin{array}{l}2 . \\
\text { derece } \\
\text { blok }\end{array}$ & $\begin{array}{l}\text { Pre } \\
\text { eksitasyon }\end{array}$ & $\begin{array}{l}\text { Idiyoventriküler } \\
\text { ritim }\end{array}$ & $\begin{array}{l}\text { Normal } \\
\text { ritim }\end{array}$ & Toplam \\
\hline ASD & 10 & 3 & 1 & - & 5 & - & - & 1 & 1 & 17 & 38 \\
\hline VSD & 4 & 7 & - & 1 & 8 & 1 & 1 & 1 & - & 14 & 37 \\
\hline TAPVD & - & - & - & - & 1 & - & - & - & - & 2 & 3 \\
\hline PAPVD & - & - & - & - & - & 1 & - & - & - & 1 & 2 \\
\hline Tek ventrikül & - & - & - & - & - & - & - & - & - & 1 & 1 \\
\hline PDA ligasyonu & 1 & - & - & - & 1 & - & - & - & - & - & 2 \\
\hline$c B A T+V S D$ & - & - & - & - & - & 1 & - & - & - & - & 1 \\
\hline AVSD & 1 & - & - & - & - & - & - & - & - & 1 & 2 \\
\hline AK & 1 & 2 & - & - & - & - & - & - & - & 4 & 7 \\
\hline PS & 1 & 2 & - & - & - & - & - & - & - & - & 3 \\
\hline FT & 1 & 2 & - & 1 & 1 & - & - & - & - & 17 & 22 \\
\hline BAT & - & 2 & - & - & - & - & - & - & - & 3 & 5 \\
\hline ÇÇRV & - & 1 & - & - & - & - & - & - & - & - & 1 \\
\hline Toplam & 19 & 19 & 1 & 2 & 16 & 3 & 1 & 2 & 1 & 60 & 124 \\
\hline$\%$ & $\% 15.3$ & $\% 15.3$ & $\% 0.8$ & \%1.6 & $\% 12.9$ & $\% 2.4$ & $\% 0.8$ & \%1.6 & $\% 0.8$ & $\% 48.4$ & $\% 100.0$ \\
\hline
\end{tabular}

AK: Aort koarktasyonu; BAT: Büyük arter transpozisyonu; cBAT: Düzeltilmiş büyük arter transpozisyonu; CCSRV: Çift çıkışlı sağ ventrikül; FT: Fallottetralojisi; PDA: Patent DuktusArteriozus; SVE: Supraventriküler ekstrasistol; VES: Ventriküler ekstrasistol; SVT: Supraventriküler taşikardi; VT: Ventriküler taşikardi; PAPVD: Parsiyelpulmonervenöz dönüş anomalisi; TAPVD: Total pulmonervenöz dönüş anomalisi

Aritmiler yapılan cerrahi prosedürler ile yakından ilişkilidir. Cerrahi manipülasyona bağlı olarak iletim sisteminin hasarlanması, postoperatif aritminin bir nedeni olup mekanik irritasyon yeri, karşılaşılan aritminin tipi ile ilişkilendirilmiştir.3,5,6 Ventriküler septal defekt onarımının çeşitli junctional ektopik taşikardi de dahil olmak üzere prematür aritmilerin, Fallottetralojisi tamiri ve Ross prosedürlerinden sonra ventriküler aritmilerin veya Senning ve Fontan operasyonları sonrasında sinüs noddis fonksiyonu ve atriyal aritmilerin daha sık görüldüğü raporlanmıştır.4,5,7 Rekawek ve $\operatorname{ark}^{8}$ ASD ve VSD onarımının, postoperatif aritmi için ilişkili risk faktörleri olduğunu bildirmişlerdir. Çalışmamıza alınan hasta grubunun çoğunu ASD ve VSD tamiri yapılmış hastalar oluşturmaktaydı. Çalışmamızda en sık görülen ritim bozuklukları literatür ile uyumlu olup SVE ve VES olarak değerlendirildi ve her ikisinin de görülme sıklığı \%15.3 saptandı. Ayrıca bu iki ritim bozukluğunun birlikte görülme oranı \% 12.9 bulundu. Bununla birlikte, mevcut serilerde kadın cinsiyetin her türlü aritmide bir risk faktörü olduğu bildirilmiştir. ${ }^{7}$ Çalışmamızda cinsiyet yönünden anlamlı fark olmasa da kızlarda SVE ve VES görülme oranının erkeklere göre daha yüksek olduğu gösterildi. Alp $\mathrm{H}$ ve ark. $^{7}$ VSD, sekundum ASD, Fallottetralojisi ve atriyoventriküler septal defekt operasyon gruplarında supraventriküler ekstra-sistolün yaygın olduğunu göstermişlerdir. Buna karşılık, başka bir çalışmada, VSD tamirinin, junctional ektopik taşikardi ve VES için bir risk olduğu bildirilmiştir. ${ }^{5}$ Çalışmamızda ASD tamiri 
yapılan hasta grubunda SVE görülme oranı daha sık olup \%26.3 saptandı. Ventriküler septal defekt tamirinde ise VES görülme oranı daha yüksek olup \%15.8 bulundu. Tüm düzeltme yapılan Fallottetralojisinde ise SVE görülme oranı \%4.5 iken VES oranı daha yüksek (\%9.1) saptand. Ayrıca ASD tamiri yapılan bir hastada supraventriküler taşikardi, VSD tamiri ve tüm düzeltme yapılan Fallottetralojisi olan iki hastada ise nonsustainedventriküler taşikardi izlendi. $\mathrm{Bu}$ bulgular, daha önceki yapılan çalışmalarda bildirildiği gibi, konjenital kalp cerrahisinden sonra ortaya çıkan geç aritmilerin, kronik hipoksemiye, cerrahi skar oluşumuna bağlı olabileceğini veya ventriküler yetersizliğin geç bir komplikasyonu olduğunu desteklemektedir.

Komplet kalp bloğu konjenital kalp cerrahisinden sonra gelişen çok ciddi bir komplikasyondur ve insidansı \%1 ila \%3 arasında değişmektedir. ${ }^{9}$ Grosse-Wortmann ve $\operatorname{ark}^{5}$ çalışmasında, kalp cerrahisinde 72 saat sonrasında çocukların \%1.1'inde atriyoventriküler blok görülürken, taburcu edilmeden önce \%3.1'e kadar yükseldiği gösterilmiștir. Başka bir çalıșmada ise, başlangıçta düzelen atriyoventriküler bloklu hastaların \%9'unda geç dönemde ikinci veya üçüncü derece blok geliştirmiştir.10 Kompletatriyoventriküler blok görülen hastalar ani ölüm riski taşırlar ve uzun süreli sağ kalım oranı azalır. ${ }^{11}$ Bizim çalışmamızda VSD tamiri yapilan bir hastada 2. derece blok saptandı. Asemptomatik olan hastanın takiplerinde kalp pili ihtiyacı olmadı.

Sonuç olarak, kardiyak operasyon geçiren çocuklarda erken ve geç postoperatif aritmi nispeten sıktır. $\mathrm{Bu}$ nedenle hastaların düzenli holter EKG izlemleri yapılmalıdır. Supraventriküler ekstra-sistol ve VES'in tüm aritmiler arasında yaygın olduğu ve bu aritmiler için ASD, VSD, Fallottetralojisi'nin risk faktörü olduğu bulundu. $\mathrm{Bu}$ veriler ışığında, en azından en sık gözlenen aritmi tipleri için cerrahi risk faktörleri belirlenebilir.

Çalışmanın retrospektif olması ve opere kompleks konjenital grubunda hasta sayılarının az olması bu çalışmanın kısıtlılıklarıdır. Ancak, daha hassas bir aritmi metodunu yansitan 24 saatlik holter EKG monitörizasyonun rutin olarak kullanılması, aritminin daha sağlıklı değerlendirilmesine neden olmuştur.

\section{Kaynaklar}

1. Lan YT, Lee JC, Wetzel G. Postoperative arrhythmia. Current Opinion in Cardiology 2003;18 (2):7378.

2. Skippen PW, Sanatani S, Gow RM, Froese N. Diagnosis of postoperative arrhythmias following paediatric cardiac surgery. Anaesthesia and Intensive Care 2009;37: 705-719.

3. Valsangiacomo E, Schmid ER, Schüpbach RW, Schmidlin D, Molinari L, Waldvogel K, Bauersfeld U. Early postoperative arrhythmias after cardiacoperation in children. The Annals of Thoracic Surgery 2002;74:792-796.

4. Pfammatter JP, Bachmann DC, Wagner BP, Pavlovic M, Berdat P, Carrel T, Pfenninger J. Early postoperative arrhythmias after openheart procedure in children with congenital heart disease. Pediatric Intensive and Critical Care Medicine 2001;2:217222.

5. Grosse-Wortmann L, Kreitz S, Grabitz RG, Vazquez-Jimenez JF, Messmer BJ, vonBernuth $\quad G$, Seghaye $\quad M C$. Prevalence of and risk factors for perioperative arrhythmias in neonates and children after cardiopulmonary by pass: continuous holter monitoring before and for three days after surgery. J Cardiothorac Surg 2010;18:85.

6. Delaney JW, Moltedo JM, Dziura JD, Kopf GS, Snyder CS. Early postoperative arrhythmias after pediatric cardiac surgery. J Thorac Cardiovasc Surg 2006;131:1296-300. 
7. Alp H, Narin C, Baysal T, Sarıgül A. Prevalence of and risk factors for early postoperative arrhythmia in children after cardiac surgery. Pediatr Int 2014;56(1):19-23.

8. Rekawek J, Kansy A, Miszczak-Knecht M, Manowska M, Bieganowska K, Brzezinska-Paszke M, Szymaniak E, Turska-Kmieć A, Maruszewski P, Burczyński P, Kawalec W. Risk factors for cardiac arrhythmias in children with congenital heart disease after surgical intervention in the early postoperative period. J Thorac Cardiovasc Surg. 2007;133:900-4.

9. Bonatti V, Agnetti A, Squarcia U. Early and late postoperative complete heart block in pediatric patients submitted to open-heart surgery for congenital heart disease. Pediatr Med Chir1998;20:181-186.

10. Weindling SN, Saul JP, Gamble WJ, Mayer JE, Wessel D, Walsh EP; Durationof complete atrioventricular block after congenital heart disease surgery. Am J Cardiol1998;82:525527.

11. Bruckheimer E, Berul CI, Kopf GS, Hill SL, Warner KA, Kleinman CS, Rosenfeld LE, Nehgme RA. Late recovery of surgicallyinducedatrioventricular block in patients with congenital heart disease. J Interv Card Electrophysiol 2002;6:191-195. 